\title{
Clinicopathological significance of CHFR promoter methylation in gastric cancer: a meta-analysis
}

\author{
Yong Ding ${ }^{1}$, Hai-Feng Lian ${ }^{2}$ and Yaowu Du$^{3}$ \\ ${ }^{1}$ School of Basic Medical Science, Henan University, Kaifeng, 475004, China \\ ${ }^{2}$ Department of Gastroenterology, Affiliated Hospital of Binzhou Medical College, Binzhou, 256600, China \\ ${ }^{3}$ Laboratory for Nanomedicine, School of Basic Medical Science, Henan University, Kaifeng, 475004, China \\ Correspondence to: Yaowu Du, email: yaowudu86weiai@hotmail.com
}

Keywords: CHFR; methylation; gastric cancer; biomarker; drug target

Received: August 21, $2017 \quad$ Accepted: November 16, $2017 \quad$ Published: December 16, 2017

Copyright: Ding et al. This is an open-access article distributed under the terms of the Creative Commons Attribution License 3.0 (CC BY 3.0 ), which permits unrestricted use, distribution, and reproduction in any medium, provided the original author and source are credited.

\section{ABSTRACT}

The mitotic checkpoint gene (CHFR) (Checkpoint with Forkhead-associated and Ring finger domains is a $\mathbf{G 2}$ phase/mitosis checkpoint and tumor-suppressor gene. Recent studies have reported the relationship of CHFR promoter methylation with clinicopathological significance of gastric cancer. However, the results remain unclear due to small size of sample. We pooled 15 studies including 827 gastric cancer patients and conducted a meta-analysis to investigate the clinicopathological significance of CHFR promoter methylation in gastric cancer. Our data revealed that the frequency of CHFR promoter methylation was higher in gastric cancer than in normal gastric tissue, Odd Ratio (OR) was 10.12 with 95\% CI 5.17-19.79, $p<0.00001$. Additionally, the rate of CHFR promoter methylation was significantly increased in high grade of gastric cancer compared to low grade, OR was 1.64 with $95 \%$ CI $1.00-2.68, p=0.05$. CHFR methylation was significantly associated with the positive lymph node metastasis, OR was 1.56 with $95 \%$ CI 1.05-2.32, $p=0.03$. We concluded that CHFR could serve as a biomarker for diagnosis of gastric cancer, and a drug target for development of gene therapy in gastric cancer. CHFR promoter methylation is associated with tumor poor differentiation and lymph node metastasis.

\section{INTRODUCTION}

Although gastric cancer (GC) incidence has significantly declined worldwide over the past a few decades, GC remains the fifth leading malignancy and the third most common cause of cancer-related mortality globally $[1,2]$. GC etiology is multifactorial, including Helicobacter pylori and Epstein-Barr virus infections environmental risk factors [3]. In addition, genetic and epigenetic alterations of oncogenes and suppressor genes contributed to the initiation and development of GC.

CHFR gene is located at chromosome 12q24.33 and contains a forkhead and a RING finger domain. It functions as a cell-cycle checkpoint molecule by delaying entry into the metaphase in response to microtubule stress. CHFR gene is silenced by promoter hypermethylation or mutated in several primary tumors such as $20 \%$ in NSCLC [4], 30\% in esophageal cancer [5], and $40 \%$ in colorectal cancer (CRC) [6]. The growing evidence supports its role as a tumor-suppressor protein and biomarker for chemotherapeutic response to microtubuletargeting drugs such as taxanes [7]. However, the rate of CHFR hypermethylation in GC was inconsistent and the relationship between CHFR methylation and clinicopathologic variables was unclear due to the small power of individual study. Our main objective was to systematically search and analyze the available studies regarding the clinicopathologic significance of $C H F R$ promoter hypermethylation in GC.

\section{RESULTS}

Identification of relevant studies and quality assessment

A total of 15 studies satisfied the inclusion criteria and were included in current meta-analysis (Figure 1), 827 GC patients and 454 controls were enrolled. All studies 
included were retrospective observational cohort studies published from 2003 to 2015. The study characteristics were summarized in Table 1. Based on the quality evaluation with the NOQAS (Newcastle-Ottawa Quality Assessment Scale), the overall quality of 15 studies was scored from six to eight which indicated good quality (data not shown).

\section{The frequency of CHFR promoter methylation} in GC and normal gastric mucosa, and the association of CHFR methylation with the grade of GC, as well as the depth of invasion

12 out of 15 studies reported the frequency of CHFR methylation in GC and normal gastric mucosa, as demonstrated in Figure 2, the frequency of $C H F R$ methylation was significantly elevated in GC compared with normal gastric mucosa, the pooled OR was 10.12, with $95 \%$ CI 5.17-19.79, $p<0.00001, I^{2}=50 \%$ (Figure 2).
The rate of CHFR methylation in different grade of GC was compared, OR was 1.64, with 95\% CI 1.00-2.68, $p=0.05, I^{2}=38 \%$, suggesting $C H F R$ gene was more frequently methylated in high grade GC than in low grade GC (Figure 3). However, there was no association between the depth of invasion in GC patients and CHFR methylation, OR was 0.85 , with $95 \%$ CI $0.48-1.52$, $p=0.59, I^{2}=0 \%$ (Figure 4$)$.

\section{The relationship of CHFR promoter methylation with stage of GC and status of lymph node metastasis}

CHFR promoter methylation was not correlated with GC stages, the frequency of CHFR promoter methylation in stage III/IV GC was not significantly increased compared to stage I/II GC, OR was $1.25,95 \%$ CI $0.82-1.91, p=0.30$ (Figure 5). The frequency of CHFR methylation in different status of lymph node metastasis was evaluated, our findings demonstrated that the CHFR

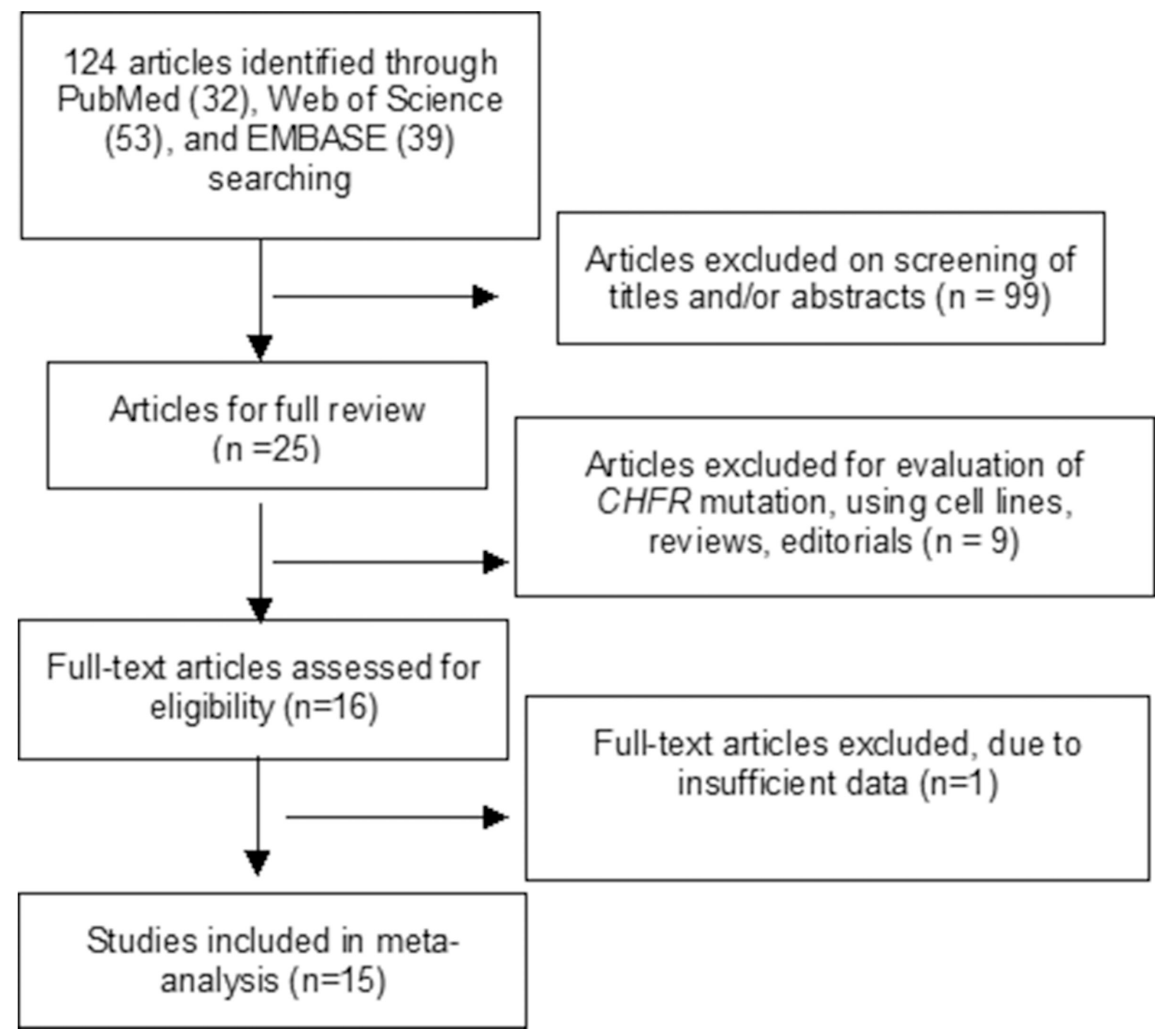

Figure 1: Schematic flow diagram for selection of included studies. 
Table 1: Main characteristics of included studies

\begin{tabular}{|c|c|c|c|c|c|c|c|c|c|c|c|c|c|}
\hline \multirow{2}{*}{ Author } & \multirow{2}{*}{ Year } & \multirow{2}{*}{ Country } & \multicolumn{2}{|c|}{ Histology } & \multicolumn{2}{|c|}{ Invasion } & \multicolumn{2}{|c|}{ Grade } & \multicolumn{2}{|c|}{ Stage(TNM) } & \multicolumn{2}{|c|}{ LN } & \multirow{2}{*}{ Method } \\
\hline & & & NCT & GC & Subserosa (-) & Subserosa(+) & $\mathbf{L}$ & H & Early & Advanced & - & + & \\
\hline $\mathrm{Li}[30]$ & 2015 & China & - & $35 / 102$ & $7 / 13$ & $28 / 89$ & $9 / 29$ & $26 / 73$ & $6 / 19$ & $29 / 83$ & $10 / 36$ & $25 / 66$ & MSP \\
\hline Wang [31] & 2014 & China & $0 / 46$ & $35 / 117$ & - & - & - & - & - & - & - & - & MethyLight \\
\hline Hiraki [32] & 2011 & Japan & $1 / 20$ & $13 / 20$ & - & - & - & - & - & - & & & MSP \\
\hline $\mathrm{Hu}$ [33] & 2010 & China & $16 / 70$ & $34 / 70$ & - & - & $8 / 25$ & $26 / 45$ & $11 / 31$ & $23 / 39$ & $7 / 23$ & $27 / 47$ & MSP \\
\hline Hiraki [34] & 2010 & Japan & $15 / 49$ & $31 / 49$ & $20 / 33$ & $11 / 18$ & - & - & $16 / 24$ & $15 / 25$ & $11 / 15$ & $20 / 34$ & MSP \\
\hline Oki [35] & 2009 & Japan & $6 / 59$ & $20 / 59$ & $8 / 23$ & $12 / 36$ & - & - & $5 / 17$ & $15 / 42$ & $5 / 20$ & $15 / 39$ & MSP \\
\hline Kang [36] & 2008 & Korea & $0 / 25$ & $11 / 25$ & - & - & - & - & - & - & & & MethyLight \\
\hline Gao [37] & 2008 & China & $0 / 20$ & $9 / 20$ & $2 / 5$ & $7 / 15$ & $0 / 6$ & $9 / 14$ & $4 / 10$ & $5 / 10$ & $3 / 8$ & $6 / 12$ & MSP \\
\hline Yoshida [38] & 2006 & Japan & $0 / 41$ & $15 / 41$ & - & - & - & - & - & - & - & - & COBRA \\
\hline Mitsuno [39] & 2007 & Japan & - & $23 / 56$ & - & - & $6 / 12$ & $10 / 26$ & $0 / 4$ & $16 / 34$ & $4 / 10$ & $12 / 28$ & MSP \\
\hline Koga [15] & 2006 & Japan & $2 / 46$ & $24 / 46$ & - & - & - & - & - & - & - & - & MSP \\
\hline Morioka [40] & 2006 & Japan & $0 / 38$ & $9 / 38$ & - & - & - & - & $4 / 16$ & $12 / 37$ & $7 / 25$ & $9 / 28$ & MSP \\
\hline Homma [41] & 2005 & Japan & $4 / 52$ & $18 / 52$ & $11 / 32$ & $7 / 20$ & - & - & $1 / 10$ & $17 / 42$ & - & - & MSP \\
\hline Honda [16] & 2004 & Japan & $4 / 34$ & $25 / 71$ & - & - & $13 / 40$ & $12 / 31$ & $6 / 15$ & $19 / 56$ & $5 / 13$ & $20 / 58$ & MSP \\
\hline Satoh [17] & 2003 & Japan & $0 / 44$ & $24 / 61$ & - & - & - & - & - & - & - & - & COBRA \\
\hline
\end{tabular}

NCT: normal control tissue; GC: Gastric Cancer; L: low grade; H: high grade; LN: Lymph node, MSP: methylation-specific PCR, COBRA: Combined Bisulfite Restriction Analysis

methylation occurred more frequently in GC patients with lymph node metastasis in contrast to the patient without lymph node metastasis. The pooled OR was 1.56 , with $95 \%$ CI $1.05-2.32, p=0.03, I^{2}=3 \%$ (Figure 6).

\section{Sensitivity analysis and publication bias}

A sensitivity analysis was conducted by omitting one study at a time, the ORs were not significantly changed, indicating the stability of present meta-analysis (Supplementary Figures 1-5). The shape of the funnel plots were largely symmetric (Figure 7), suggesting there was no publication biases existed in the meta-analysis of association between $C H F R$ promoter methylation and clinicopathological variables.

\section{DISCUSSION}

The lack of CHFR gene was initially observed in colorectal cancer and neuroblastoma cell lines by Scolnik and Halazonetis, then loss of CHFR expression has been reported in a number of malignancies including colorectal cancer $[6,8,9]$, esophageal cancer $[5,10]$, NSCLC [11-13] and gastric cancer [14-17]. Previous evidence indicated CHFR was mostly inactivated by its promotor $\mathrm{CpG}$ island methylation [18]. CHFR promoter methylation has been evaluated in $\mathrm{GC}$, however, the frequency was inconsistent due to small size of samples. We pooled 12 studies together and compared the frequency of CHFR promoter methylation in $827 \mathrm{GC}$ with 454 nonmalignancy gastric mucosa, the result indicated that

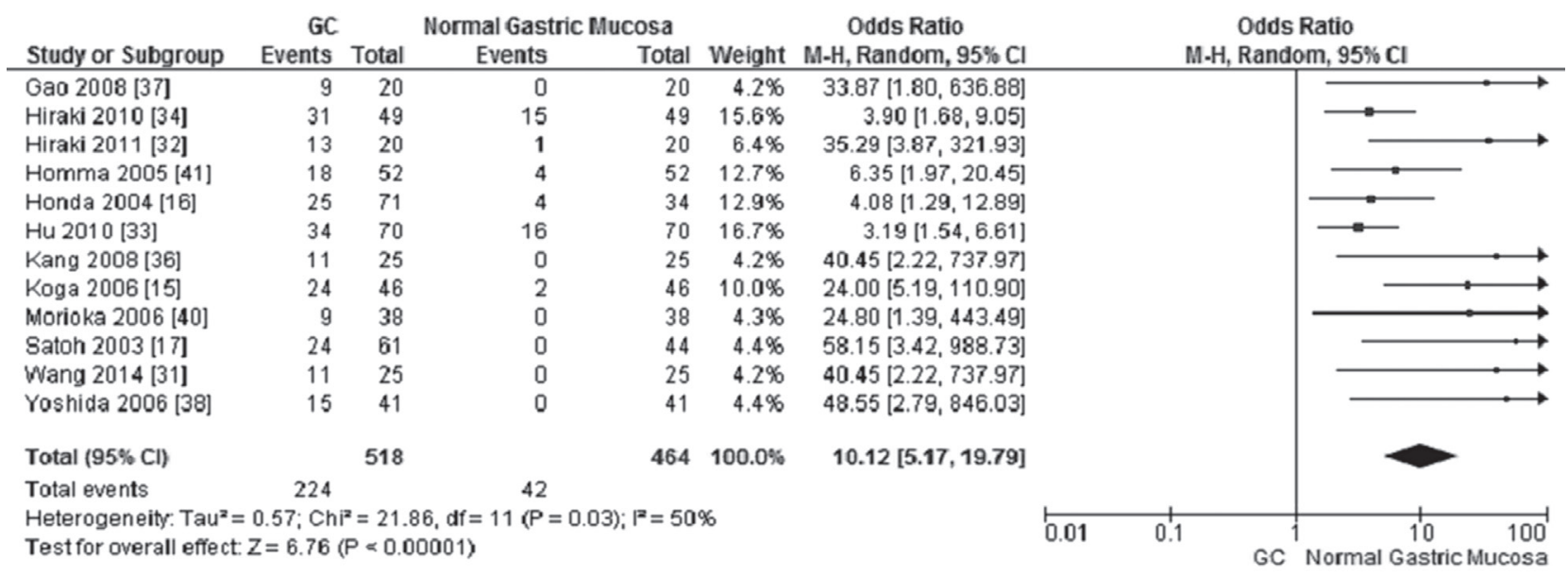

Figure 2: Forest plot for CHFR promoter methylation in GC and normal gastric tissue. 
CHFR promoter methylation in GC was 10.12 times higher than in non-malignancy gastric mucosa. Our result was consistent with previous meta-analysis [19]. Previous evidence indicated that CHFR ubiquitinates and binds to both polo-like-kinase (PLK1) and Aurora A, results in the inhibition of phosphorylation of Cdc25 [20-23]. The cyclin B1-Cdk complex is not able to form and the cell cycle is arrested in G2 phase [23, 24]. Thus, cells with CHFR gene inactivated by promoter methylation cannot be arrested in the G2 phase and proceed to mitosis, leading to abnormal proliferation and differentiation. Therefore, CHFR promoter methylation is associated with the risk of $\mathrm{GC}$ incidence.
Further subgroup analysis revealed that $C H F R$ promoter methylation was associated with poor differentiation of GC. However, the mechanism is unclear and further investigation needs to be finished in future.

Additionally, our finding indicated that $C H F R$ promoter methylation was strongly associated with lymph node metastasis. Previous evidence showed that abnormal CHFR expression down-regulated histone deacetylase 1 and promoted the expression of $p 21^{\mathrm{CIP} 1 /}$ WAF1 and metastasis suppressors kangai 1 and E-cadherin [25]. Recent studies indicated that reduced kangai 1 expression was associated with lymph node metastasis [26]. Additionally, CHFR act as a negative regulator of

\begin{tabular}{|c|c|c|c|c|c|c|c|c|c|c|}
\hline \multirow[b]{2}{*}{ Study or Subgroup } & \multicolumn{2}{|c|}{ High grade } & \multicolumn{2}{|c|}{ Low grade } & \multirow[b]{2}{*}{ Weight } & \multirow{2}{*}{$\begin{array}{l}\text { Odds Ratio } \\
\text { M-H, Fixed, } 95 \% \mathrm{Cl}\end{array}$} & \multirow{2}{*}{\multicolumn{4}{|c|}{$\begin{array}{c}\text { Odds Ratio } \\
\text { M.H, Fixed, } 95 \% \mathrm{Cl}\end{array}$}} \\
\hline & Events & Total & Events & Total & & & & & & \\
\hline Gao 2008 [3]] & 9 & 14 & 0 & 6 & $1.0 \%$ & $22.45[1.05,479.93]$ & & & & \\
\hline Honda 2004 [16] & 12 & 31 & 13 & 40 & $27.9 \%$ & $1.31[0.49,3.49]$ & & & & \\
\hline Hu 2010 [33] & 26 & 45 & 8 & 25 & $17.4 \%$ & $2.91[1.04,8.13]$ & & & & \\
\hline Li 2015 [30] & 26 & 73 & 9 & 29 & $33.3 \%$ & $1.23[0.49,3.09]$ & & & & \\
\hline Mitsuno 2007 [39] & 10 & 26 & 6 & 12 & $20.3 \%$ & $0.63[0.16,2.48]$ & & & & \\
\hline Total $(95 \% \mathrm{Cl})$ & & 189 & & 112 & $100.0 \%$ & $1.64[1.00,2.68]$ & & & & \\
\hline Total events & 83 & & 36 & & & & & & & \\
\hline \multicolumn{7}{|c|}{$\begin{array}{l}\text { Heterogeneity: } C i^{2}=6.45, d f=4(P=0.17) ; P^{2}=38 \% \\
\text { Test for overall effect: } Z=1.95(P=0.05)\end{array}$} & 0.01 & 0.1 High grade & Low grade & 100 \\
\hline
\end{tabular}

Figure 3: Forest plot for $C H F R$ promoter methylation in different grade of GC.

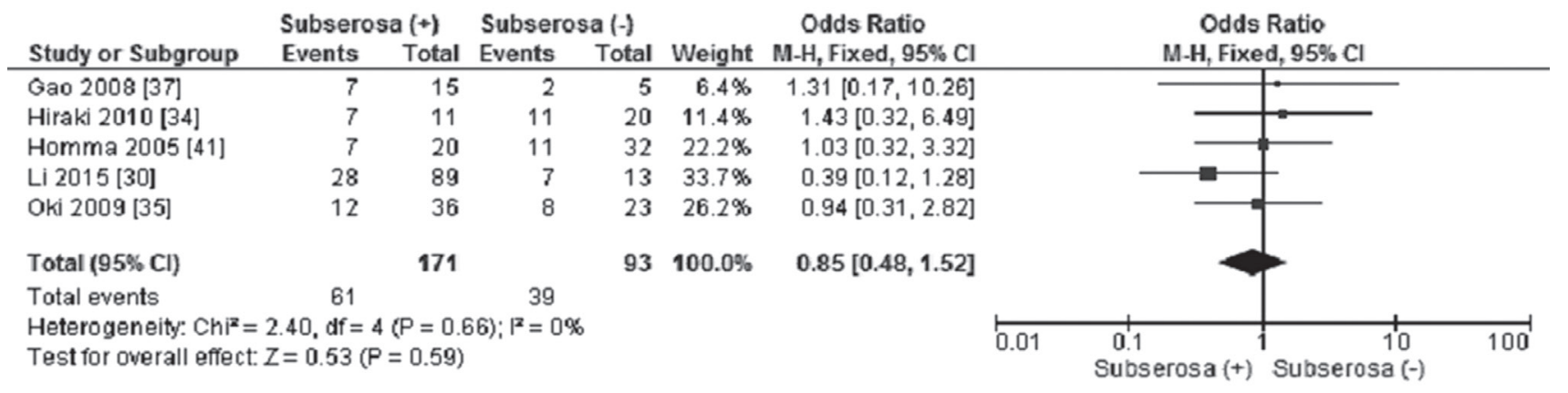

Figure 4: Forest plot for CHFR promoter methylation in different invasion status of GC.

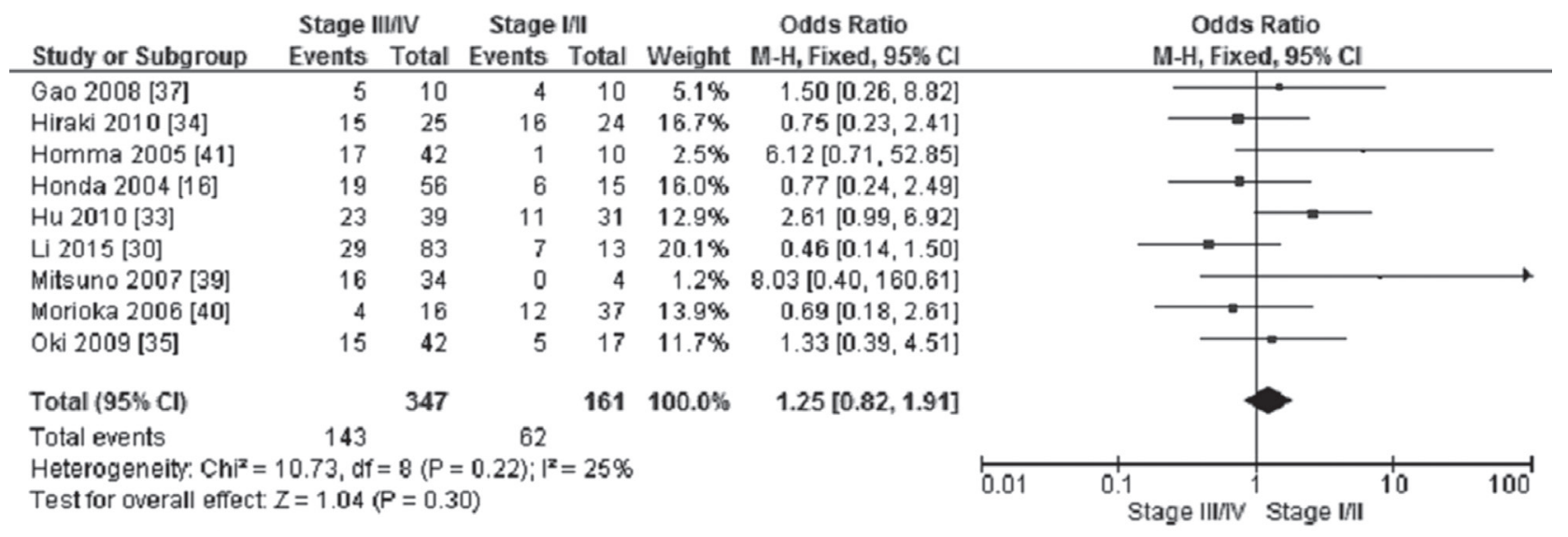

Figure 5: Forest plot for CHFR promoter methylation in GC stage III/IV and stage I/II. 
the nuclear factor $\mathrm{kB}$ pathway, whereas $\mathrm{kB}$ activation contributes to lymph node metastasis [27, 28]. Thus, CHFR promoter methylation is correlated with lymph node metastasis in $\mathrm{GC}$.

A few limitations of this meta-analysis should be noted. First, present findings were based on the patients from Asia, cautions should be taken when the findings are interpreted among the general populations. Second, publication bias may exist, as positive results were more likely published. Third, the possibility of information and selection biases as well as unidentified confounders could not be completely excluded because all of the included studies were observational.

In summary, $C H F R$ promoter methylation is associated with the risk of GC development. CHFR could be a potential biomarker for diagnosis and a drug target of personalized treatment for the patients with GC.
CHFR promoter methylation is correlated with GC poor differentiation and positive lymph node metastasis.

\section{MATERIALS AND METHODS}

\section{Study identification}

We performed a systematic literature search for articles published from the earliest available data to November 2017 in PubMed, EMBASE, and Web of Science with no limit set for date and language. The search terms were " $\mathrm{CHFR}$, or Checkpoint with Forkhead-associated and Ring finger domains" and "gastric cancer", "GC", "methylation". We conducted a manual search and reviewed the reference lists of include studies for any further relevant citations.

After screening by titles and abstracts, individual studies were screened using the inclusion and exclusion

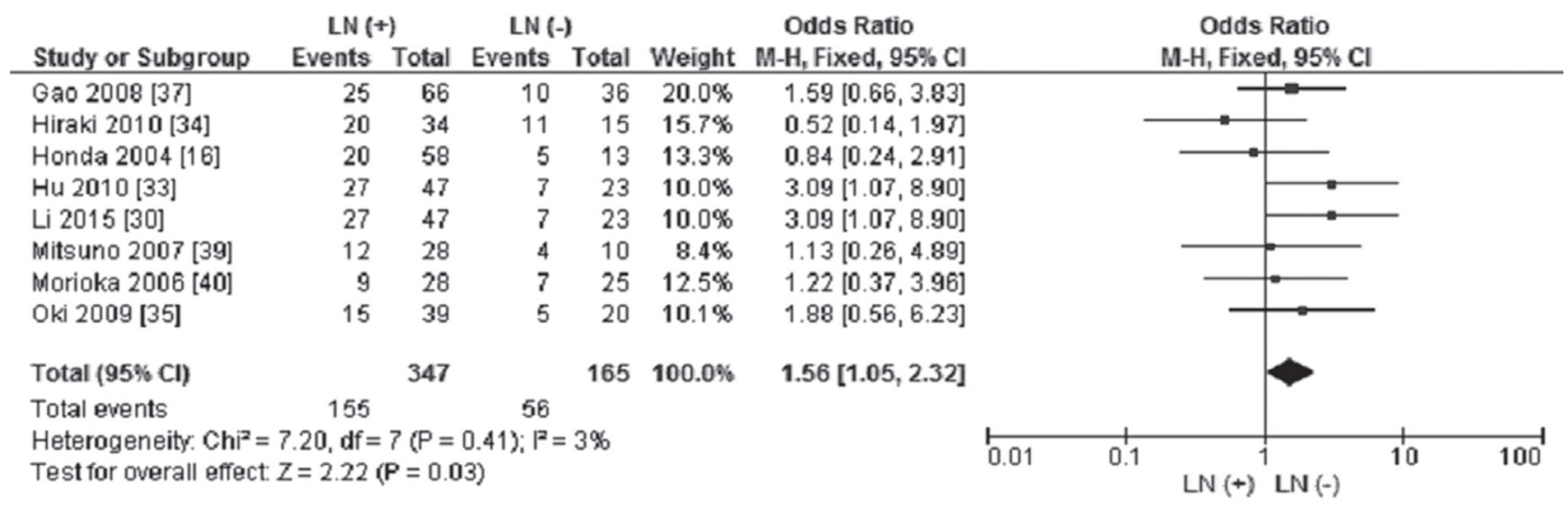

Figure 6: Forest plot for $C H F R$ promoter methylation in different status of lymph node metastasis.
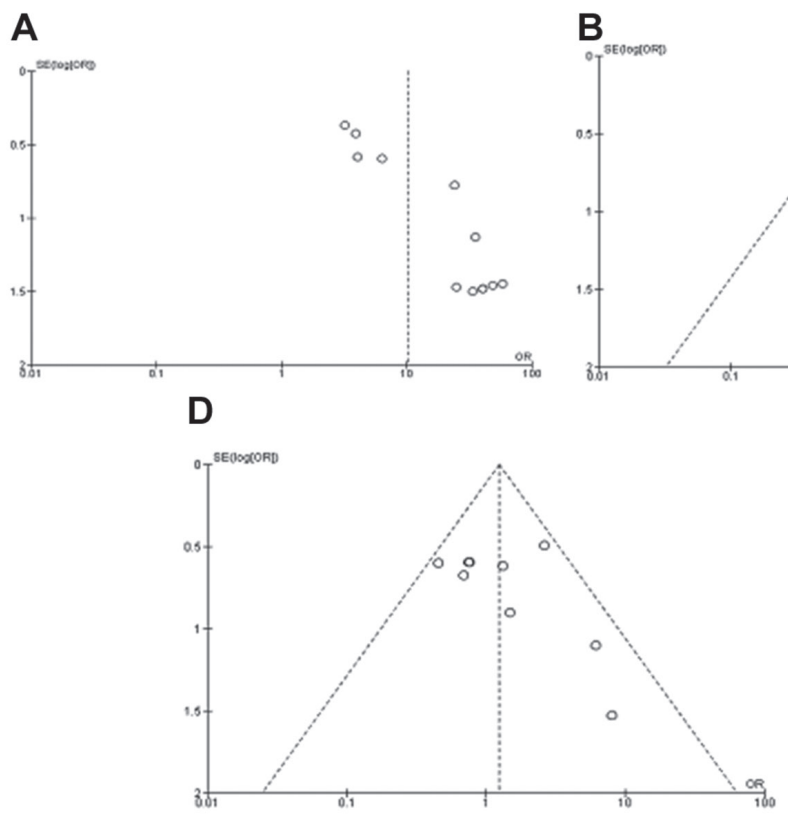
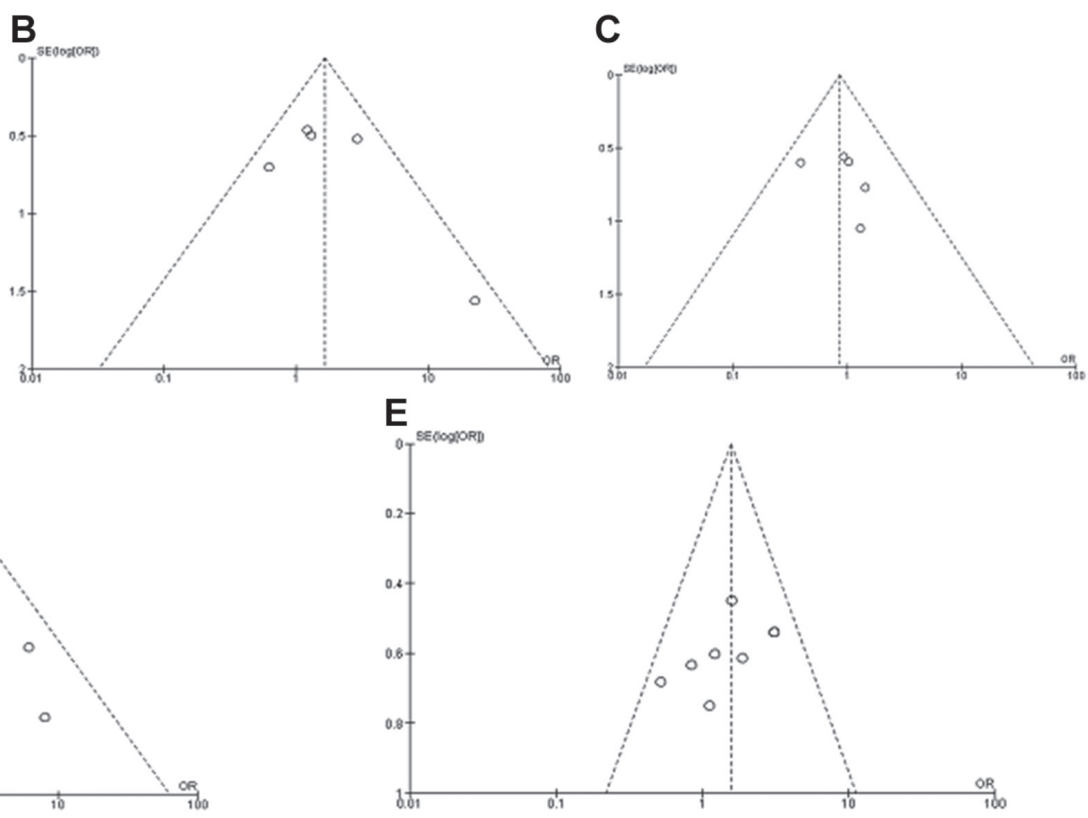

Figure 7: Funnel plot for publication bias. (A) $C H F R$ promoter methylation in GC and normal gastric tissue; (B) $C H F R$ promoter methylation in high and low grade of GC; (C) CHFR promoter methylation in different invasion status of GC; (D) CHFR promoter methylation in GC stage III/IV and stage I/II; (E) CHFR promoter methylation in different status of lymph node metastasis. 
criteria. We included studies that met the following criteria: 1) CHFR hypermethylation evaluated in GC tissue; 2) Study revealed the relationship between $C H F R$ hypermethylation and GC clinicopathological variables. Exclusion criteria included the following: 1) studies using cell line and human xenografts, as well as using the same population and overlapping database. 2) reviews, conference abstracts, editorials, letters, case reports, and expert opinion. The flow chart of searches was shown in Figure 1.

\section{Data extraction}

Primary data were extracted by using a customized form that included first author, year of publication, geography location, the number of case, the depth of invasion, GC TNM stages, grades and methylation detect methods. Two authors independently extracted data, any discrepancies were discussed until a consensus was reached as a first step, then by consultation with the senior study investigator if consensus was not reached.

\section{Quality assessment}

The methodological quality of included studies was evaluated based on NOQAS. This scale was used to allocate a maximum of nine points, $0-4$ points for selection, 0-2 points for comparability, 0-3 points for outcomes. The NOS scores ranged from 0 to 9 , and a score $\geq 7$ indicates a good quality. All studies were assessed by HL and YDu independently, any disagreements were discussed until a consensus was reached.

\section{Statistical analysis}

The pooled ORs with its $95 \%$ confidence intervals were calculated. The heterogeneity among studies was determined by using the Cochran's Q statistic and $I^{2}$ tests. When the $I^{2}$ value was below $50 \%$, fixed effect model was used, when the $I^{2}$ value was $50 \%$ or greater, a random effect model was used. An Egger's test for asymmetry of funnel was used to assess for publication bias [29]. The analysis was performed to compare the frequency of CHFR methylation between GC and normal gastric mucosa. The frequency of $C H F R$ hypermethylation was compared in different tumor characteristics. The pooled ORs were estimated for the correlation between $C H F R$ hypermethylation and clinicopathological features. The meta-analysis was performed using Review Manager 5.3 (Cochrane Collaboration, Software Update, Oxford, UK). $P$ values tailed less than 0.05 were considered statistically significant.

\section{Author contributions}

YD, HL and YDu carried out the study, participated in collecting data and drafting the manuscript. HL and YD performed the statistical analysis and participated in its design. YDu and HL have been involved in drafting and the critical revision of the manuscript. The corresponding author had full access to all data and the final responsibility for the decision to submit the article for publication. All authors read and approved the final manuscript.

\section{CONFLICTS OF INTEREST}

The authors declare that they have no competing interests or financial disclosures.

\section{REFERENCES}

1. Graham DY. Helicobacter pylori update: gastric cancer, reliable therapy, and possible benefits. Gastroenterology. 2015; 148:719-731 e713.

2. Balakrishnan M, George R, Sharma A, Graham DY. Changing Trends in Stomach Cancer Throughout the World. Curr Gastroenterol Rep. 2017; 19:36.

3. Correa P. Gastric cancer: overview. Gastroenterol Clin North Am. 2013; 42:211-217.

4. Mizuno K, Osada H, Konishi H, Tatematsu Y, Yatabe Y, Mitsudomi T, Fujii Y, Takahashi T. Aberrant hypermethylation of the CHFR prophase checkpoint gene in human lung cancers. Oncogene. 2002; 21:2328-2333.

5. Shibata Y, Haruki N, Kuwabara Y, Ishiguro H, Shinoda N, Sato A, Kimura M, Koyama H, Toyama T, Nishiwaki T, Kudo J, Terashita Y, Konishi S, et al. Chfr expression is downregulated by $\mathrm{CpG}$ island hypermethylation in esophageal cancer. Carcinogenesis. 2002; 23:1695-1699.

6. Toyota M, Sasaki Y, Satoh A, Ogi K, Kikuchi T, Suzuki H, Mita H, Tanaka N, Itoh F, Issa JP, Jair KW, Schuebel KE, Imai K, Tokino T. Epigenetic inactivation of CHFR in human tumors. Proc Natl Acad Sci U S A. 2003; 100:7818-7823.

7. Privette LM, Petty EM. CHFR: A Novel Mitotic Checkpoint Protein and Regulator of Tumorigenesis. Transl Oncol. 2008; 1:57-64.

8. Derks S, Postma C, Carvalho B, van den Bosch SM, Moerkerk PT, Herman JG, Weijenberg MP, de Bruine AP, Meijer GA, van Engeland M. Integrated analysis of chromosomal, microsatellite and epigenetic instability in colorectal cancer identifies specific associations between promoter methylation of pivotal tumour suppressor and DNA repair genes and specific chromosomal alterations. Carcinogenesis. 2008; 29:434-439.

9. Kawasaki T, Ohnishi M, Nosho K, Suemoto Y, Kirkner GJ, Meyerhardt JA, Fuchs CS, Ogino S. CpG island methylator phenotype-low (CIMP-low) colorectal cancer shows not only few methylated CIMP-high-specific $\mathrm{CpG}$ islands, but also low-level methylation at individual loci. Mod Pathol. 2008; 21:245-255.

10. Soutto M, Peng D, Razvi M, Ruemmele P, Hartmann A, Roessner A, Schneider-Stock R, El-Rifai W. Epigenetic and 
genetic silencing of CHFR in esophageal adenocarcinomas. Cancer. 2010; 116:4033-4042.

11. Takeshita M, Koga T, Takayama K, Yano T, Maehara Y, Nakanishi Y, Sueishi K. Alternative efficacy-predicting markers for paclitaxel instead of CHFR in non-small-cell lung cancer. Cancer Biol Ther. 2010; 10:933-941.

12. Koga T, Takeshita M, Yano T, Maehara Y, Sueishi K. CHFR hypermethylation and EGFR mutation are mutually exclusive and exhibit contrastive clinical backgrounds and outcomes in non-small cell lung cancer. Int J Cancer. 2011; 128:1009-1017.

13. Guo M, Alumkal J, Drachova T, Gao D, Marina SS, Jen J, Herman JG. CHFR methylation strongly correlates with methylation of DNA damage repair and apoptotic pathway genes in non-small cell lung cancer. Discov Med. 2015; 19:151-158.

14. Kang HC, Kim IJ, Park JH, Shin Y, Park HW, Ku JL, Yang HK, Lee KU, Choe KJ, Park JG. Promoter hypermethylation and silencing of CHFR mitotic stress checkpoint gene in human gastric cancers. Oncol Rep. 2004; 12:129-133.

15. Koga Y, Kitajima Y, Miyoshi A, Sato K, Sato S, Miyazaki $\mathrm{K}$. The significance of aberrant CHFR methylation for clinical response to microtubule inhibitors in gastric cancer. J Gastroenterol. 2006; 41:133-139.

16. Honda T, Tamura G, Waki T, Kawata S, Nishizuka S, Motoyama T. Promoter hypermethylation of the Chfr gene in neoplastic and non-neoplastic gastric epithelia. $\mathrm{Br} \mathrm{J}$ Cancer. 2004; 90:2013-2016.

17. Satoh A, Toyota M, Itoh F, Sasaki Y, Suzuki H, Ogi K, Kikuchi T, Mita H, Yamashita T, Kojima T, Kusano M, Fujita M, Hosokawa M, et al. Epigenetic inactivation of CHFR and sensitivity to microtubule inhibitors in gastric cancer. Cancer Res. 2003; 63:8606-8613.

18. Derks S, Cleven AH, Melotte V, Smits KM, Brandes JC, Azad N, van Criekinge W, de Bruine AP, Herman JG, van Engeland M. Emerging evidence for CHFR as a cancer biomarker: from tumor biology to precision medicine. Cancer Metastasis Rev. 2014; 33:161-171.

19. Shi H, Wang X, Wang J, Pan J, Liu J, Ye B. Association between CHFR gene hypermethylation and gastric cancer risk: a meta-analysis. Onco Targets Ther. 2016; 9:7409-7414.

20. Li J, Williams BL, Haire LF, Goldberg M, Wilker E, Durocher D, Yaffe MB, Jackson SP, Smerdon SJ. Structural and functional versatility of the FHA domain in DNAdamage signaling by the tumor suppressor kinase Chk2. Mol Cell. 2002; 9:1045-1054.

21. Privette LM, Weier JF, Nguyen HN, Yu X, Petty EM. Loss of CHFR in human mammary epithelial cells causes genomic instability by disrupting the mitotic spindle assembly checkpoint. Neoplasia. 2008; 10:643-652.

22. Vader G, Lens SM. The Aurora kinase family in cell division and cancer. Biochim Biophys Acta. 2008; 1786:60-72.

23. Yu X, Minter-Dykhouse K, Malureanu L, Zhao WM, Zhang D, Merkle CJ, Ward IM, Saya H, Fang G, van Deursen J,
Chen J. Chfr is required for tumor suppression and Aurora A regulation. Nat Genet. 2005; 37:401-406.

24. Burgess A, Labbe JC, Vigneron S, Bonneaud N, Strub JM, Van Dorsselaer A, Lorca T, Castro A. Chfr interacts and colocalizes with TCTP to the mitotic spindle. Oncogene. 2008; 27:5554-5566.

25. Oh YM, Kwon YE, Kim JM, Bae SJ, Lee BK, Yoo SJ, Chung CH, Deshaies RJ, Seol JH. Chfr is linked to tumour metastasis through the downregulation of HDAC1. Nat Cell Biol. 2009; 11:295-302.

26. Protzel C, Kakies C, Kleist B, Poetsch M, Giebel J. Downregulation of the metastasis suppressor protein KAI1/ CD82 correlates with occurrence of metastasis, prognosis and presence of HPV DNA in human penile squamous cell carcinoma. Virchows Arch. 2008; 452:369-375.

27. Kashima L, Toyota M, Mita H, Suzuki H, Idogawa M, Ogi K, Sasaki Y, Tokino T. CHFR, a potential tumor suppressor, downregulates interleukin-8 through the inhibition of NFkappaB. Oncogene. 2009; 28:2643-2653.

28. Yan M, Xu Q, Zhang P, Zhou XJ, Zhang ZY, Chen WT. Correlation of NF-kappaB signal pathway with tumor metastasis of human head and neck squamous cell carcinoma. BMC Cancer. 2010; 10:437.

29. Egger M, Davey Smith G, Schneider M, Minder C. Bias in meta-analysis detected by a simple, graphical test. BMJ. 1997; 315:629-634.

30. Li Y, Yang Y, Lu Y, Herman JG, Brock MV, Zhao P, Guo M. Predictive value of CHFR, MLH1 methylation in human gastric cancer. Gastric Cancer. 2015; 18:280-287.

31. Wang M, Shen L, Deng D. Association between CHFR methylation and chemosensitivity of paclitaxel in advanced gastric cancer. Med Oncol. 2014; 31:907.

32. Hiraki M, Kitajima Y, Koga Y, Tanaka T, Nakamura J, Hashiguchi K, Noshiro H, Miyazaki K. Aberrant gene methylation is a biomarker for the detection of cancer cells in peritoneal wash samples from advanced gastric cancer patients. Ann Surg Oncol. 2011; 18:3013-3019.

33. Hu SL, Kong XY, Cheng ZD, Sun YB, Shen G, Xu WP, Wu L, Xu XC, Jiang XD, Huang DB. Promoter methylation of p16, Runx3, DAPK, CHFR genes is frequent in gastric carcinoma. Tumori. 2010; 96:726-733.

34. Hiraki M, Kitajima Y, Sato S, Mitsuno M, Koga Y, Nakamura J, Hashiguchi K, Noshiro H, Miyazaki K. Aberrant gene methylation in the lymph nodes provides a possible marker for diagnosing micrometastasis in gastric cancer. Ann Surg Oncol. 2010; 17:1177-1186.

35. Oki E, Zhao Y, Yoshida R, Masuda T, Ando K, Sugiyama M, Tokunaga E, Morita M, Kakeji Y, Maehara Y. Checkpoint with forkhead-associated and ring finger promoter hypermethylation correlates with microsatellite instability in gastric cancer. World J Gastroenterol. 2009; 15:2520-2525.

36. Kang GH, Lee S, Cho NY, Gandamihardja T, Long TI, Weisenberger DJ, Campan M, Laird PW. DNA methylation profiles of gastric carcinoma characterized 
by quantitative DNA methylation analysis. Lab Invest. 2008; 88:161-170.

37. Gao YJ, Xin Y, Zhang JJ, Zhou J. Mechanism and pathobiologic implications of CHFR promoter methylation in gastric carcinoma. World J Gastroenterol. 2008; 14:5000-5007.

38. Yoshida K, Hamai Y, Suzuki T, Sanada Y, Oue N, Yasui W. DNA methylation of CHFR is not a predictor of the response to docetaxel and paclitaxel in advanced and recurrent gastric cancer. Anticancer Res. 2006; 26:49-54.

39. Mitsuno M, Kitajima Y, Ide T, Ohtaka K, Tanaka M, Satoh S, Miyazaki K. Aberrant methylation of p16 predicts candidates for 5-fluorouracil-based adjuvant therapy in gastric cancer patients. J Gastroenterol. 2007; 42:866-873.

40. Morioka Y, Hibi K, Sakai M, Koike M, Fujiwara M, Kodera Y, Ito K, Nakao A. Aberrant methylation of the CHFR gene in digestive tract cancer. Anticancer Res. 2006; 26:1791-1795.

41. Homma N, Tamura G, Honda T, Jin Z, Ohmura K, Kawata $\mathrm{S}$, Motoyama T. Hypermethylation of Chfr and hMLH1 in gastric noninvasive and early invasive neoplasias. Virchows Arch. 2005; 446:120-126. 